\title{
The Effect of Acute Plasmodium falciparum Infection on the levels of Malondialdehyde (MDA) and Ascorbic acid on Nigerian Children
}

\author{
*ISAMAH, G K; ASAGBA, S O \\ Department of Biochemistry, Delta State University, P.M.B. I, Abraka, Della State, Nigeria
}

\begin{abstract}
The effect of acute plasmodium falcipartum infection on the levels of malondialdehyde (MDA) and ascorbic acid (AA) were studied in 200 children infested with malaria between the ages of $0.5-5$ years with a male to female ratio of 3:1. Healthy children $(n=200)$ matched for age and sex ratio served as control. MDA content was significantly higher $(P<0.01)$ in the plasma of malarias children $(13.88 \pm 1.02$ $\mu \mathrm{mol} / \mathrm{ml})$ compated to the control $(8.71 \pm 0.62 \mu \mathrm{mol} / \mathrm{ml})$. However, AA level showed an opposite response: malarias children $(87.41 \pm 3.43 \mu \mathrm{mol} / \mathrm{ml})$ and control $(122.07 \pm 6.36 \mu \mathrm{mol} / \mathrm{ml})$. These results were also highly significant $(P<0.01)$. Also a negative correlation $(r=0.525)$ was observed between these two parameters in the malarias children against a positive correlation $(r=0.533)$ in the control. These opposite responses in the level of lipid peroxidation and ascorbic acid may in part account for the general tissue damage associated with the pathology of malaria. @JASEM
\end{abstract}

Almost all of the estimated over one million deaths from malaria each year worldwide are attributable to Plasmodium falciparam and are in children up to 5 years old who live in areas of intense transmission of $P$. falciparum especially in Sub-Saharan Africa (Campbell, 1991; WHO, 2000). The importance of reactive oxygen intermediates in host defence against parasitic infections is well known. Activated oxygen species are toxic to plasmodia and are important components of the host's defenses against malaria (Adelekan and Thurnham, 1998). Golenser and Chevion (1989) reported an increase in the concentration of MDA, a lipid peroxidation product in the blood of mice infection with $P$. berghei. Ascorbic acid (AA), the reduced form of vitamin C, is an importance cofactor in several enzyme reactions and plays a pivotal role in the defence against oxidative stress (Levine, 1986; Gambhir et al., 1997); whereas the oxidized form, dehydroascorbic acid (DHAA) is considered a marker of oxidative stress (Ayaori et al., 2000). So far, the effect of acute plasmoduim faciparum infection on the level of malondiadehyde and ascorbic acid in malarious children has been unreported. Therefore, the present study was designed to elucidate the correlation between these two parameters in Nigerian children infected with plasmodium falciparum

\section{MATERIALS AND METHODS}

The survey was carried out between June 2000 and October 2001 in Benin City, Edo State in the western Niger-Delta where malaria is endemic. Children $(n=$ $200)$; age range $(0.5-5$ years) with a male to female ratio of 3:1 were selected from those admitted to University of Benin Teaching Hospital Benin City.
These children were febrile (rectal temperature between $36^{\circ} \mathrm{C}$ and $41^{\circ} \mathrm{C}$ ), had positive blood smear for $P$. falciparum asexual parasites with a count greater than $100,000 / \mu l$; showed inability to take medications by mouth, altered consciousness and severe anaemia (haemoglobin $<5 \mathrm{~g} / \mathrm{d} l$ ). These patients already receiving antimalarial drugs at home before admission were excluded in this study. Healthy children $(n=200)$ matched for age and sex ratio served as control. The details of the study were explained to the mothers of the subjects and verbal consents to participate were obtained.

Venous blood samples were obtained from the subjects. Blood was collected into sterile tubes containing EDTA as anticoagulant and plasma was separated by centrifugation $(625 \mathrm{x} \mathrm{g}$ for $15 \mathrm{~min})$ at room temperature. Aliquots of the plasma samples were assayed immediately for ascorbic acid content due to its significant decrease with incubation (Levine 1986). The remainder was stored frozen at $20^{\circ} \mathrm{C}$ and analysed for the level of lipid peroxidation within one week of storage.

Plasma thiobarbituric acid reactive substances (TBARS) levels were determined by colorimetric assay as essentially reported by Gutteridge and Wilkins (1982). Values for TBARS are reported as MDA equivalents (Buege and Aust 1978). Plasma samples were acidified with $5 \%$ metaphosphoric acid ( 5 vol. of plasma plus 1 vol. of the acid) and AA content determined by titration with 2,6dichlorophenolindophenol (Plummer 1978). Values were expressed as mean \pm S.E.M. The significance of the mean difference between groups were assessed by 
the student's $\mathrm{t}$ - test. The correlation coefficient was determined by linear regression analysis.

\section{RESULTS AND DISCUSSION}

One of the notable features of malaria infection is the activation of the cellular immune system and production of reactive oxygen species (ROS) by phagocytes (Mohan et al., 1994). The ROS are implicated in both protection and pathogenesis of this infection.

Table 1 shows that plasmodium falciparum infection significantly $(\mathrm{P}<0.01)$ increased the level of $\mathrm{MDA}$ in the malarious children comparable to the control children. One consequence of the peroxidation of a biomembrane is a decrease in the fluidity of the lipid phase of the membrane assembly (Slater et al., 1987). These changes may increase the chance of erythrocyte lyses during microcirculation, thus increasing their vulnerability to premature destruction. The high level of MDA in the malarious children is not surprising since $P$. falciparum has been established to utilize and deplete the host antioxidant mechanisms, like catalase, superoxide dismutase and glutathione peroxidase (Mohan et al., 1994).

Table 1. Levels of lipid Per-oxidation and Ascorbic Acid in Malarias and Control Children

\begin{tabular}{llll}
\hline Parameters & Malarias children & Control children \\
\hline Lipid Peroxidation & ${ }^{x} 13.88 \pm 1.02$ & $\mathrm{n}=200$ & $8.71 \pm 0.62 \quad \mathrm{n}=200$ \\
(MDA $\mu \mathrm{mol} / \mathrm{m} \ell)$ & & & \\
Ascorbic acid $(\mu \mathrm{mol} / \mathrm{L})$ & ${ }^{x \times} 87.41 \pm(3.43)$ & $\mathrm{n}=200$ & $122.07 \pm 6.36 \quad \mathrm{n}=200$ \\
\hline
\end{tabular}

Results are expressed as mean \pm standard error of mean (S.E.M) ${ }^{x x}$ Statistically significant $(p<0.01)$ using student's t-test $n=$ number of subjects.

The MDA level reported in this study for $P$. falciparum infected individual $(13.88 \pm 1.02$ $\mu \mathrm{mol} / \mathrm{mml})$ greatly in excess compared to the result $(3.40 \pm 1.07 \mathrm{nmol} / \mathrm{ml})$ obtained with adult Indians with falciparum malaria complications and those $(4.40 \pm 0.47 \mathrm{nmol} / \mathrm{m} l)$ that expired (Rath et al., 1991). The differences obtained in our study may be a reflection of the endemicity of the study area and the ages of our subjects $(0.5-5$ years). Malaria is less common in adults due to enhanced immunity (WHO 2000). Therefore, the enhanced level of lipid peroxidation in the malarious children could be an index of oxidative damage.

$P$. falciparum infection significantly reduced $(\mathrm{P}<$ 0.01 ) the level of ascorbic acid in the malarious children as compared to the control children (table 1). Ascorbic acid is reversibly oxidised to dehydroascorbic acid (Levine, 1986) and the radical scavenging capacity of AA disappears when transformed to DHAA (Gill et al., 1999). Increased plasma level of dehydroascorbate suggests an enhanced turnover of ascorbic acid possibly in response to sustained oxidant load (Duthie et al., 1991; Kacmaz of al., 1997). The decrease in the content of $\mathrm{AA}$ in malarious children may shift the redox of AA in favour of DHAA and this altered redox status could be suggestive of oxidative stress arising from plasmodium infection.

There was a negative correlation $(r=-0.525)$ between the levels of ascorbic acid and lipid peroxidation in malarious children compared to a positive correlation $(r=0.533)$ in the control children. Frei (1994) reported that ascorbic acid forms the first line of antioxidant defence in human plasma exposed to a variety of oxidant insults and once used up, there is initiation of lipid per-oxidation. The apparent efficacy of ascorbic acid is not surprising given the depleted level of this vitamin that has been established in the malarious children. Indeed, the contribution of total anti-oxidant activity in percentage terms of ascorbate to $\alpha$-tocopherol is $15: 5$ (Slater et al., 1987). Our data have shown that a high level of lipid per oxidation with a concomitant compromised level of ascorbic acid could be quantitative indices of plasmodium falciparum infection in Nigerian children.

Acknowledgement: To the members of staff of the Department of Medical Microbiology and parasitology of the University of Benin Teaching Hospital, Benin City, we express our profound gratitude for their assistance in the collection of blood sample.

\section{REFERENCES}

Adelekan, D A, Thurnham, D I (1998). Glutathione Peroxidase and superoxide dismutase activities in riboflavin-deficient rats infected with plasmodium berghei malaria J Nutr 79:305-309.

Ayori, M; Hisada, T; Suzukawa, M; Yoshida, H (2000). Plasma level and redox status of ascorbic 
acid levels of lipid peroxidation products in active and passive smokers. Environ Health Prspect 108:105-108.

Buege, J A; Aust, S D (1978). Microsomal Lipid Peroxidation In: Fleischer P; Packer, L. (eds) Methods in Enzymology vol. 52 Academic press, New York, pp. 302-310

Campbell, C C (1991). Challenges facing antimalarial therapy in Africa. J Infect Dis 163:1207-1211.

Duthie, G G; Arthur, J R; James, W P T (1991). Effect of smoking and vitamin $E$ on blood antioxidant status. Am J Clin Nutr 53:1061S$1063 \mathrm{~S}$.

Frei, B (1994). Reactive oxygen species and antioxidant vitamins: mechanisms of action. Am J Med 97: (Suppl. 3A) 3A-5S-3A-13S

Gambhir, J K; Lali, P; Jain, A K (1997). Correlation between blood antioxidant levels and lipid peroxidation in rheumatoid arthritis. Clin Biochem 30:351-355.

Gill, M I; Ferreres, G; Tomas-Barberan, F.A (1999) Effects of postharvest storage and processing on the antioxidant constituents (flavonoids and vitamin C) on fresh-cut spinach. J Agric Food Chem 47:2213-2217

Golenser, J; Chevion, M (1989). Oxidant stress and malaria. Host-Parasite interrelationships in normal and abnormal erythrocytes. Semin Hematol 26:313-325.

Gutteridge, J M C; Wikins, S (1982). Copperdependent hydroxyl radical damage to ascorbic acid. Formation of thiobarbituric acid reactive product. FEBS Letts 337:327-300.

Kacmaz, M; Ozturk, S H; Cete, S (1997). The effect of smoking on antioxidant defence system and membrane free fatty acid content of erythrocytes and plasma lipid parameters: protective role of antioxidant vitamins. Nutr Res 17:931-940.

Levine, $M(1986)$. New concepts in the biology and biochemistry of ascorbic acid. $N$ Engl J Med 314:821-879.

Mohan, K; Dubey, M L; Ganguly, N K; Mahajan, R C (1994). Plasmodium falciparum and blood monocytes abnomalities in human erythrocyte cation homeostasis. Immunol cell Biol 72:285291.

Plummer, D T (1978). Introduction to Practical Biochemistry. $2^{\text {nd }}$ edn. Mac Graw-Hill, NewYork.

Rath, R N; Panigraphi, B K; Das, P K (1991). Lipid peroxidation in acute falciparum malaria. Indian J Med Res [A] 93:303-305

Slater, T F; Cheeseman K H; Davies, M J; Proudfoot, $\mathrm{K}$; Xin, W (1987). Free radical mechanisms in relation to tissue injury. Proc. Nutr Soc 46:1-12. 